\title{
Traditional Warfarin (Coumadin) Therapy Usage Experience on Nonvalvular Atrial Fibrillation before Non-Vitamin K Antagonists (New Oral Anticoagulants) Era from a Center in Turkey
}

\author{
Emre Özdemir, Özgen Safak', Sadik Volkan Emren, Mehmet Serdar Bayata \\ Cardiology Clinic, Atatürk Education and Research Hospital, Katip Çelebi University, Izmir, ${ }^{1}$ Cardiology Clinic, Balikesir University, Balikesir, Turkey \\ ORCID: \\ Emre Özdemir: https://orcid.org/0000-0003-0034-3022 \\ Özgen Safak: https://orcid.org/0000-0001-8245-0117 \\ Sadik Volkan Emren: https://orcid.org/0000-0002-7652-1123 \\ Mehmet Serdar Bayata: https://orcid.org/0000-0002-2186-1817
}

\section{Abstract}

Introduction: Atrial fibrillation (AF) is the most common arrhythmia with a prevalence that increases by aging. AF causes morbidity and mortality due to thromboembolic events. In developing countries, the use of new generation medications can be delayed. Objective: We evaluated nonvalvular AF patients without effective oral anticoagulation (OAC) when non- vitamin K antagonists (NOACs) were mostly unavailable in Turkey before 2012-2013. The results were compared with what would happen if NOAC was available in use. Patients and Methods: Two-hundred and five patients in AF with adequate information were detected 123 of these patients were nonvalvular AF, (92 patients in these 123 ones were not taking OAC or on ineffective INR range) were included in the study. Results: Thirty-one $(25.2 \%)$ of these patients were already on effective warfarin therapy. Ninety-two $(74.8 \%)$ patients were not on warfarin therapy or on out of effective therapeutic range. About $52.2 \%$ of participants were female. The mean age was $70.62 \pm 11.8$ years. Eighteen (19.5\%) patients had a recurrent stroke. Conclusion: OACs are recommended for patients with high stroke risk according to CHA2DS2-VASc score. OAC therapy significantly decreases mortality, morbidity, and also especially stroke risk. The only OAC therapy was warfarin over the decades until NOACs have been found. In our study, if NOACs could be available before 2012 in Turkey, $74.8 \%$ of our cohort would be under the effective anticoagulation and $19.5 \%$ of patients may have avoided from stroke. This is important for patients' lives and also for their costs.

Keywords: Atrial fibrillation, nonvalvular atrial fibrillation, novel oral anticoagulants, warfarin, warfarin

\section{INTRODUCTION}

Atrial fibrillation (AF) is the most common supraventricular arrhythmia with a prevalence that increases by aging. There is no structural heart disease in a considerable portion of patients with AF. AF causes significant morbidity and mortality due to the thromboembolic events. ${ }^{[1]}$

$\mathrm{AF}$ is a strong independent risk factor for ischemic stroke (IS) due to the thromboembolic events and increases the risk of IS 5-folds; by the way, all ISs $(20 \%-30 \%)$ associated with $\mathrm{AF}^{[2]}$ The presence of associated structural heart diseases in AF further

Received: 18-11-2019 Revised: 13-12-2019 Accepted: 02-01-2020

Published Online: 11-06-2020

\begin{tabular}{|l|l|}
\hline \multicolumn{3}{c|}{ Access this article online } \\
\hline Quick Response Code: & Website: \\
& http://www.ijcva.com \\
& \\
&
\end{tabular}

increases the stroke risk. IS which is a dramatic complication of AF is still an important issue because of its mortality, morbidity, adult disability, and incurred costs, as it was before.

Currently, in the light of previous studies, the most effective treatment for preventing such an important and dramatic complication secondary to AF is oral anticoagulant

Address for correspondence: Dr. Emre Özdemir, Cardiology Clinic, Atatürk Education and Research Hospital, Katip Çelebi University, Izmir 35620, Turkey. E-mail: emreozdemir27@yahoo.com.tr

This is an open access journal, and articles are distributed under the terms of the Creative Commons Attribution-NonCommercial-ShareAlike 4.0 License, which allows others to remix, tweak, and build upon the work non-commercially, as long as appropriate credit is given and the new creations are licensed under the identical terms.

For reprints contact: WKHLRPMedknow_reprints@wolterskluwer.com

How to cite this article: Özdemir E, Safak Ö, Emren SV, Bayata MS. Traditional warfarin (Coumadin) therapy usage experience on nonvalvular atrial fibrillation before non-Vitamin $\mathrm{K}$ antagonists (new oral anticoagulants) era from a center in Turkey. Int J Cardiovasc Acad 2020;6:66-9. 
(OAC) therapy. ${ }^{[3]}$ Randomized controlled studies have shown that OAC therapy achieving effective levels decreases IS risk by $68 \%$ in unselected AF patients. ${ }^{[4]}$ Furthermore, even though NOAC (new oral anticoagulation) drugs such as dabigatran, rivaroxaban, apixaban, and edoxaban are available, except for these OAC treatments, with no real recommendation, acetylsalicylic acid and clopidogrel can use to prevent thromboembolic complications by some clinicians.

Recently, the most widespread treatment in our country and the world was warfarin, but in the past 3 years, rapidly, NOACs became the most preferred OAC therapy. The problems occurred due to the international normalised ratio (INR) lability for the patient and the physician were effective in this change.

In this study, patients were evaluated when access to NOACs is more difficult, because of no reimbursement agency's repayment in the past, so the patients had AF diagnosis according to the criteria in the European Society of Cardiology (ESC) 2010 AF treatment guideline and updated guideline. ${ }^{[5,6]}$ It is easier to switch to a NOAC after 2012 in Turkey because the reimbursement problem solved. We compared INR control in the years when there were no reimbursement agencies NOAC repayment and there was NOAC repayment after the year 2013 conditions.

\section{Patients and Methods}

\section{Subjects and research design}

Our study was registered in the ethics committee of our hospital as a retrospective screening study. According to the general working principle in our clinic, all procedures were made with patient approval (Date: November 05, 2018, number: 2018-GOKAE-0538).

\section{Data collection}

The medical records of patients that use warfarin in our clinic which is a tertiary health institution between January 2010 and September 2012 were screened. Our study had a retrospective cohort, and we had 212 patients with I48 International Classification of Diseases (ICD) diagnosis code. Patients ( $n$ : 7) with inadequate hospital records were excluded from the study. Two-hundred and five patients in AF with adequate information were detected, 123 of these patients were nonvalvular $\mathrm{AF}$ (92 patients in these 123 ones were not taking OAC or on ineffectiveINR range) were included in the study. We evaluated demographical, clinical, and echocardiographic parameters of these patients. Patients with valvular AF and other NOAC (like glomerular filtration rate [GFR] under 15) contraindications according to the current guidelines were excluded. ${ }^{[5,6]}$

Our patients were evaluated in three groups according to the AF period: paroxysmal AF episodes lasting $<7$ days with spontaneous resolution, persistent $\mathrm{AF}$ episodes lasting $>7$ days and requiring medical intervention for resolution, and permanent AF patients who have chronic $\mathrm{AF}^{[5]}$

For the OAC's indication and risk of bleeding, CHA2DS2-VASc and HAS-BLED scores were used. Patients with a HAS-BLED score of $\geq 3$ were considered as having a high risk for bleeding, and in patients with a CHA2DS2-VASc score of $\geq 2$, anticoagulant therapy is recommended ${ }^{[5-8]}$ According to the medical records, the reasons of patients with no therapy were determined (patients' rejection and clinicians' option). Effective therapeutic range for INR was accepted as labile 2-3 range of INR in more than $70 \%$, on least monthly INR tests of the follow-up period. ${ }^{[9]}$

\section{Statistical analysis}

Quantitative data are shown as mean \pm standard deviation in tables. Categorical data were shown as number (n) and percentage (\%). In an analysis of quantitative data conformity with normal distribution, Kolmogorov-Smirnov test was used. In assessing the findings of the study, statistical analysis of data was done using the Statistical Package for the Social Sciences 15.0 for Windows (IBM, Chicago, USA).

\section{RESULTS}

We collected 123 patients who were eligible for both warfarin and NOAC therapy. Thirty-one (25.2\%) of these patients were already on warfarin therapy in effective therapeutic range and ongoing follow-up, so they are excluded from the study. Ninety-two (74.8\%) patients who were not on warfarin therapy or already using warfarin but out of effective therapeutic range were noted.

Patients' sex distribution was 44 (47.8\%) males and 48 (52.2\%) females [Table 1]. The mean age was $70.62 \pm 11.8$ years [Table 2]. Paroxysmal AF in $23(25.0 \%)$, persistent AF in $29(31.5 \%)$, and permanent $\mathrm{AF}$ in $40(43.5 \%)$ patients were detected. Most frequent comorbid disease was hypertension and detected in $80(87.0 \%)$ patients. Five (5.4\%) patients had hyperthyroidism [Table 1].

Thirteen (14.1\%) of these 92 patients were not on warfarin therapy due to physicians' hesitate and $41(44.6 \%)$ of them were not under to a reason of patients' hesitation. A $1.1 \%$ rate in the physicians' hesitates were HAS-BLED score $\geq 3$ and other rates were clinicians' unknown options. Two $(2.2 \%)$ of patients had a bleeding history, and because of the fear of bleeding repetition, patients rejected warfarin usage. Other $55.4 \%$ of the patients' reason could not be obtained. On the

\begin{tabular}{lc}
\hline Table 1: Patient's clinical data & \\
\hline Variable & $\boldsymbol{n}(\%)$ \\
\hline Gender & \\
Male & $44(47.8)$ \\
Female & $48(52.2)$ \\
Arterial hypertension & $80(87)$ \\
Diabetes mellitus & $16(17.4)$ \\
Smoking & $53(67.6)$ \\
Hyperthyroidism & $5(5.4)$ \\
Paroxysmal atrial fibrillation & $23(25)$ \\
Persistent atrial fibrillation & $29(31.5)$ \\
Permanent atrial fibrillation & $40(43.5)$ \\
\hline
\end{tabular}


other hand, 38 (41.3\%) of them were using warfarin, but they were out of effective therapeutic range or not in a regular follow-up. Totally, $58.7 \%$ ( $n: 54)$ of 92 patients were not on warfarin therapy despite they had an indication. As a paradox due to the hesitate of physician or patient, $7.2 \%$ of 54 patients were using clopidogrel + acetylsalicylic acid and $51.5 \%$ only acetylsalicylic acid therapy [Table 3].

The mean HAS-BLED score was $2.39 \pm 0.97$. Sixty (65.2\%) patients had a HAS-BLED score $<3$. The mean CHA2DS2-VASc score was $3.68 \pm 1.71$ [Table 2].

The mean ejection fraction was $53.96 \% \pm 11.6 \%$, the mean left atrial diameter was $44.27 \pm 6.2 \mathrm{~mm}$, and the mean GFR was $93.4 \pm 31.9 \mathrm{~mL} / \mathrm{min}$ [Table 2].

The CHA2DS2-VASc score distribution was 1 in 9 (9.8\%) patients and $\geq 2$ in $83(90.2 \%)$ patients. In 7 patients with a CHADS score of 0, CHA2DS2-VASc score was calculated, it was found between 1 and 5. Seven patients without OAC indication according to the CHADS score got an indication for OAC usage according to the CHA2DS2-VASc score. Furthermore, only 2 patients in $\geq 2$ CHA2DS2-VASc score were female.

Moreover, as the most impressive result of our study, eighteen (19.5\%) patients had a new stroke $>24$ hour after the current stroke that defined as recurrent stroke. There was no hemorrhagic event for our cohort.

\begin{tabular}{|c|c|}
\hline Variable & \\
\hline Age (year) & $70.6 \pm 11.8$ \\
\hline Hemoglobin (mg/dL) & $12.2 \pm 1.7$ \\
\hline Glomerular filtration rate $(\mathrm{mL} / \mathrm{min})$ & $93.4 \pm 31.9$ \\
\hline Serum creatinine $(\mathrm{mg} / \mathrm{dL})$ & $0.80 \pm 0.18$ \\
\hline CHA2DS2-VASc score & $3.68 \pm 1.71$ \\
\hline HAS-BLED score & $2.39 \pm 0.97$ \\
\hline Left ventricular ejection fraction (\%) & $53.96 \pm 11.6$ \\
\hline Left atrial diameter (mm) & $44.27 \pm 6.2$ \\
\hline
\end{tabular}

\begin{tabular}{lc}
\hline $\begin{array}{l}\text { Table 3: Data of patients with ineffective or none usage } \\
\text { of warfarin }\end{array}$ \\
\hline Variable & $\boldsymbol{n}(\%)$ \\
\hline Patient without warfarin therapy & \\
$\quad$ Clinicians' option & $12(13)$ \\
$\quad$ Clinicians' option, reason unknown & $1(1.1)$ \\
$\quad$ Clinicans' option, high HAS-BLED score & \\
Patient's refusal & $39(42.4)$ \\
$\quad$ Patient's refuse, reason unknown & $2(2.2)$ \\
$\quad$ Patient's refuse, bleeding story & \\
Patients with warfarin therapy & $12(13)$ \\
Ineffective INR & $26(28.3)$ \\
\hline Using warfarin but ineffective INR \\
$\quad$ Using warfarin but no follow-up
\end{tabular}

Our mean follow-up period was 1157 days.

\section{Discussion}

$\mathrm{AF}$ is the most frequent arrhythmia in the general population. Its prevalence increases by aging and reaches to $3.7 \%-4.2 \%$ in $60-70$ years and increased to $10 \%-17 \%$ after 80 years. ${ }^{[10]}$

Currently, most feared complication of AF is stroke. Stroke risk can calculate with the CHA2DS2-VASc score by the most accepted method. CHA2DS2-VASc score of congestive heart failure, hypertension, diabetes, vascular disease, age of 65-74 years, and sex (female) is 1 point, and the score of stroke and age $\geq 75$ is 2 points ${ }^{[6]}$ Risk of stroke decreases markedly with effective OAC therapy in AF patients with high risk for stroke ${ }^{[11]}$ Cerebral ischemia associated with nonvalvular AF is over $7 \%$ annually. ${ }^{[12]}$ Current guidelines and studies suggest NOACs to warfarin because of superior effects of NOACs.

A meta-analysis based on NOACs treatment showed, 19\% reduced stroke or systemic embolic events, a decrease in hemorrhagic stroke and total mortality rate was $10 \%$, but gastrointestinal bleeding events were more frequent of NOACs compared with warfarin. ${ }^{[13]}$ On this way the superiority of NOACs compared with warfarin and by the easier access to NOAC compared to the past, today, NOACs have increased in popularity as a first choice inappropriate nonvalvular AF patients. 2016 ESC Guidelines suggest as class internal auditor recommendation that when oral anticoagulation is initiated in a patient with $\mathrm{AF}$ who is eligible for a NOAC (apixaban, dabigatran, edoxaban, or rivaroxaban), a NOAC can prefer to a Vitamin K antagonist. ${ }^{[6]}$

Studies show that effective OAC treatment is often at low rates, and stroke prophylaxis in high-risk patients became a challenge. ${ }^{[14]}$

From the past to recent days, the unique oral anticoagulant therapy has been possible with warfarin. Warfarin is a sufficient anticoagulant, but because of the warfarin's narrow therapeutic range, it is hard to anticoagulate patients with effective dosages, and also, under the third of them had a warfarin dosage in the effective range. Due to this situation, traditional warfarin therapy of patients with AF could not be reduced the risk of IS. ${ }^{[14]}$ However, NOAC became accessible since 2012, and reimbursement agency started to repayment since 2013.

About $25 \%$ of AF patients are associated with stroke risk, and the prognosis of stroke due to $\mathrm{AF}$ is worse than non-AF strokes because of comorbid diseases ${ }^{[15]}$ The rate of recurrence of stroke is also higher. ${ }^{[16]}$ Wang et al. reported that all NOACs had lower thromboembolic and bleeding events but not on all-cause mortality. ${ }^{[17]}$ In our study, $19.5 \%$ ( $n$ : 18) of nontreated 92 patients with AF had an IS episode on follow-up. If we could add patients without follow-up or unreachable on record, these IS events were getting probably more frequent. The most important factor that increases the cost of stroke in the acute period is hospitalization. Costs are significantly higher in patients with $\mathrm{AF}$, because in these cases, the stroke became more severe due to concomitant 
comorbidities. ${ }^{[18]}$ Hence, in the lights of these data, the costs of NOACs can be more cost-effective than ineffective range warfarin therapy.

Our study's mean age was $70.62 \pm 11.8$ years. These data are similar with other studies, but we had higher rates for female patients $(52.2 \%)$ than other studies. ${ }^{[19]}$

Our mean HAS-BLED score was $2.39 \pm 0.97$ and paroksismal AF was $25 \%$. This is similar with Methavigul and Methavigul data. ${ }^{[20]}$

In our study, we found that mean CHA2DS2-VASc was $3.68 \pm 1.71$; these data are similar with Lee at al.'s study. ${ }^{[21]}$

According to a meta-analysis of randomized controlled trials by Costello et al., NOACs had lower stroke rates compared with warfarin. ${ }^{[22]}$ In our study, we found that $92(74.8 \%)$ patients $(38,[41.3 \%$ ] of these patients were on ineffective oral anticoagulation therapy and $54[58.7 \%]$ patients were not on anticoagulant therapy) were at risk of stroke due to lack of appropriate treatment and also 18 patients had an IS. If NOAC usage was started before 2012-2013, these patients could be protected against ischemic events. This situation is important for the patients' life and also for the costs.

\section{Conclusion}

$\mathrm{AF}$ is the most common arrhythmia and stroke risk is more frequent for $\mathrm{AF}$ patients compared to patients without AF. OAC therapy is recommended for patients with high stroke risk. The most common OAC therapy is warfarin over the decades. OAC therapy significantly decreases the risk of mortality, morbidity, and stroke, which means why this therapy is especially important for OAC patients.

Inadequate and incomplete use of warfarin therapy significantly increases the stroke, stroke-based mortality, hospitalization rate, and economic costs. In our study's data, if NOACs could be available before 2012 in Turkey, $74.8 \%$ of our cohort would be under the effective anticoagulation and $19.5 \%$ of accessed patients would not have a stroke, as a maximum rate.

\section{Limitations}

Major limitation of our study is being retrospective and data's limitations in the hospital records. Furthermore, unwanted biases could not be excluded because accessible recorded patients were included.

\section{Financial support and sponsorship \\ Nil.}

\section{Conflicts of interest}

There are no conflicts of interest.

\section{RefERENCES}

1. Kannel WB, Abbott RD, Savage DD, McNamara PM. Epidemiologic features of chronic atrial fibrillation: The Framingham study. N Engl J Med 1982;306:1018-22.

2. Reiffel JA. New versus traditional approaches to oral anticoagulation in patients with atrial fibrillation. Am J Med 2014;127:e15.

3. Hart RG, Halperin JL, Pearce LA, Anderson DC, Kronmal RA,
McBride $\mathrm{R}$, et al. Warfarin versus aspirin for prevention of thromboembolism in atrial fibrillation Stroke Prevention in Atrial Fibrillation II study. Lancet 1994;343:687-91.

4. Rockson SG, Albers GW. Comparing the guidelines: Anticoagulation therapy to optimize stroke prevention in patients with atrial fibrillation. J Am Coll Cardiol 2004;43:929-35.

5. European Heart Rhythm Association, European Association for Cardio-Thoracic Surgery, Camm AJ, Kirchhof P, Lip GY, Schotten U, et al. Guidelines for the management of atrial fibrillation: The Task Force for the Management of Atrial Fibrillation of the European Society of Cardiology (ESC). Eur Heart J 2010;31:2369-429.

6. Kirchhof P, Benussi S, Kotecha D, Ahlsson A, Atar D, Casadei B, et al. 2016 ESC Guidelines for the management of atrial fibrillation developed in collaboration with EACTS. Eur Heart J 2016;37:2893-962.

7. Gage BF, Waterman AD, Shannon W, Boechler M, Rich MW, Radford MJ. Validation of clinical classification schemes for predicting stroke: Results from the National Registry of Atrial Fibrillation. JAMA 2001;285:2864-70.

8. Pisters R, Lane DA, Nieuwlaat R, de Vos CB, Crijns HJ, Lip GY. A novel user-friendly score (HAS-BLED) to assess 1-year risk of major bleeding in patients with atrial fibrillation: The Euro Heart Survey. Chest 2010;138:1093-100.

9. Camm AJ, Lip GY, De Caterina R, Savelieva I, Atar D, Hohnloser SH, et al. 2012 focused update of the ESC Guidelines for the management of atrial fibrillation: An update of the 2010 ESC Guidelines for the management of atrial fibrillation - Developed with the special contribution of the European Heart Rhythm Association. Europace 2012;14:1385-413.

10. Zoni-Berisso M, Lercari F, Carazza T, Domenicucci S. Epidemiology of atrial fibrillation: European perspective. Clin Epidemiol 2014;6:213-20.

11. Wolf PA, Abbott RD, Kannel WB. Atrial fibrillation as an independent risk factor for stroke: The Framingham Study. Stroke 1991;22:983-8

12. Hart RG, Halperin JL. Atrial fibrillation and thromboembolism: A decade of progress in stroke prevention. Ann Intern Med 1999;131:688-95.

13. Ruff CT, Giugliano RP, Braunwald E, Hoffman EB, Deenadayalu N, Ezekowitz MD, et al. Comparison of the efficacy and safety of new oral anticoagulants with warfarin in patients with atrial fibrillation: A meta-analysis of randomised trials. Lancet 2014;383:955-62.

14. Guerriero F, Orlando V, Monetti VM, Colaccio FM, Sessa M, Scavone C, et al. Predictors of new oral anticoagulant drug initiation as opposed to warfarin in elderly adults: A retrospective observational study in Southern Italy. Ther Clin Risk Manag 2018;14:1907-14.

15. Steger C, Pratter A, Martinek-Bregel M, Avanzini M, Valentin A, Slany J, et al. Stroke patients with atrial fibrillation have a worse prognosis than patients without: Data from the Austrian Stroke registry. Eur Heart J 2004;25:1734-40.

16. Kultursay H. Atrial fibrillation, epidemiology and association with stroke. Arch Turk Soc Cardiol 2013;41 Supp 4:1-4.

17. Wang X, Fang L, Liu B, Zheng Y, Zeng J. Real-world comparisons of reduced-dose non-vitamin $\mathrm{K}$ antagonist oral anticoagulants versus warfarin in atrial fibrillation: A systematic review and meta-analysis. Heart Fail Rev 2019;1-11.

18. Brüggenjürgen $\mathrm{B}$, Rossnagel $\mathrm{K}$, Roll $\mathrm{S}$, Andersson $\mathrm{FL}$, Selim D, Müller-Nordhorn J, et al. The impact of atrial fibrillation on the cost of stroke: The berlin acute stroke study. Value Health 2007;10:137-43.

19. Park JH, Han SW, Lee KY, Choi HY, Cheon K, Cho HJ, et al. Impact of Non-vitamin K Antagonist Oral Anticoagulant Withdrawal on Stroke Outcomes. Front Neurol 2018:9:1095.

20. Methavigul K, Methavigul R. Use of simplified HAS-BLED score in patients with atrial fibrillation receiving warfarin. J Arrhythm 2019;35:711-5.

21. Lee KT, Chang SH, Yeh YH, Tu HT, Chan YH, Kuo CT, et al. The $\mathrm{CHA}_{2} \mathrm{DS}_{2}$-vasc score predicts major bleeding in non-valvular atrial fibrillation patients who take oral anticoagulants. J Clin Med 2018;7. pii: E338.

22. Costello M, Murphy R, Judge C, Ruttledge S, Gorey S, Loughlin E, et al. Effect of NOACs on Stroke Severity Compared to Warfarin: A Meta-analysis of Randomized Controlled Trials. European journal of neurology, 2019 